\title{
A CPFD MODEL TO INVESTIGATE THE INFLUENCE OF FEEDING POSITIONS IN A GASIFICATION REACTOR
}

\author{
RAJAN JAISWAL, NORA C. I. S. FURUVIK, RAJAN K. THAPA \& BRITT M. E. MOLDESTAD \\ Department of Natural Science and Maritime Science, University of South-Eastern Norway, Porsgrunn, Norway.
}

\begin{abstract}
The efficiency of a gasification process is directly related to the rate of biomass conversion into product gas. The rate of fuel conversion depends on the interaction of fuel with the bed material, the gasifying agent, and the residence time of fuel particles. The interactions and the residence time depend on the fuel feeding positions along the height of the reactor. Thus, the fuel feeding position in a gasification reactor is an important parameter that influences the efficiency of the gasification process; longer residence time of the fuel particles in the bed enables efficient carbon conversion and less tar formation. In this work, in-bed and on-bed feed positions of the fuel particles have been investigated using a computational particle fluid dynamics (CPFD) model. The model is developed and validated against experimental data obtained from a bubbling fluidized bed gasification reactor. Experiments were carried out in a $20 \mathrm{~kW}$ pilot scale bubbling fluidized bed gasification reactor. Wood pellets of 3-30 mm length and $5 \mathrm{~mm}$ diameter are fed into the reactor at a mass flow rate of $2.4 \mathrm{~kg} / \mathrm{h}$. The molar flow rate of the producer gas, which typically consists of $\mathrm{CH}_{4}, \mathrm{CO}, \mathrm{CO}_{2}$, and $\mathrm{H}_{2}$ for both the in-bed and on-bed cases, is calculated by the CPFD model. The results show that $\mathrm{CO}$ and $\mathrm{CH}_{4}$ concentrations increase in the product gas when the biomass is fed at the location near to the bottom of the bed, while $\mathrm{CO}_{2}$ and $\mathrm{H}_{2}$ increase in the case of on-bed feed. The fuel particles segregate, followed by partial combustion of the smaller fuel particles on the bed surface in the case of on-bed feed. The total mass of the bed including unreacted char is higher for on-bed feed, indicating that the char is consumed slowly. The CPFD model can predict the product gas compositions, the fuel conversion, changes in the bed hydrodynamics, and the product gas yield at different feeding positions of the fuel particles. Thus, the model can be useful for design purposes.

Keywords: computational particle fluid dynamics, feed positions, fluidized bed, gasification, wood pellets.
\end{abstract}

\section{INTRODUCTION}

Gasification of biomass is a sustainable conversion technology to cope with an increasing environmentally friendly energy demand. The interest for gasification using fluidized bed is growing, since the process provides uniform heat transfer and fuel flexibility [1]. Ideal mixing of the fuel particles, the bed material, and the gas phase promotes excellent heat transfer in a fluidized bed. The efficiency of the gasification process is determined by the conversion rate of biomass (to the product gas) [2]. The conversion of solid biomass into producer gas is a complex thermochemical process that occurs in several steps. The first step is drying and devolatilization. The volatile components are released as soon as the biomass is fed into the reactor, and this step is known as pyrolysis. The char remaining after volatilization of biomass is gasified at temperatures in the range of $700^{\circ} \mathrm{C}-800^{\circ} \mathrm{C}$ using steam or air as the gasifying agent. For a given feedstock, the quality of the product gas is dependent on the air to fuel ratio [3, 4], the temperature of the reactor [3], the residence time of fuel in the reactor $[5,6]$, and the feed position [7]. The feed position of biomass to the reactor influences the distribution of biomass inside the bed, and thus the fuel conversion efficiency. The conversion rate of biomass is dependent on the contact time between the biomass and the gasifying agent and the amount of heat the biomass requires for chemical conversion. The density difference between the bed material and the biomass causes particles to segregate in a fluidized bed. 
Furthermore, the lift force exerted by the gas bubbles that envelops the biomass during devolatilization transports the lower-density and larger-size biomass to the surface of the bed [8, 9]. The segregation of biomass is more intense in the case of on-bed feed as the biomass tends to remain on the surface of the bed, increasing the residence time. The residence time of the biomass can be estimated based on the transportation time of the biomass between two reference locations, the relative amount of the fuel participating in reactions, and the time elapsed before complete conversion of the biomass is achieved [6].

Several experimental works have been conducted on the on-bed and in-bed feed of fuel in the past. Ross et al. [10] used a lab-scale bubbling fluidized bed to study the influence of feed positons. They measured the gas compositions at different axial locations and found a higher concentration of $\mathrm{C}_{1}-\mathrm{C}_{3}$ hydrocarbons when the feed position was on the bed surface. In another work, Vriesman et al. [11] studied the influence of feed positions on the nitrogen conversion into $\mathrm{NH}_{3}$ and $\mathrm{HCN}$ in a fluidized bed gasifier at different temperatures and equivalence ratios. They found that the feed positions do not influence the product gas. Di Celso et al. [12] investigated the influence of feed positions on fluidized bed gasification and concluded that the in-bed feed position has improved carbon conversion compared to on-bed feeding. There is very limited literature available to illustrate the effect of feed positions in the gasifier using a computational particle fluid dynamics (CPFD) model.

In this work, a CPFD model is developed using the commercial software Barracuda to study the influence of the feed position. Experimental data are obtained from gasification of wood pellets in a pilot-scale bubbling fluidized bed reactor. A computational setup is developed and the results from the simulations are compared with experimental data to validate the model. The CPFD model is used to study the influence of on-bed and in-bed feed positions on the product gas yields, char conversion, and bed behavior. The CPFD model developed in this work can be used to design and study a pilot-scale and industrial scale gasifier.

\section{EXPERIMENTAL STUDY OF BIOMASS GASIFICATION}

\subsection{Experimental setup}

The experimental setup consists of a cylindrical reactor with inner diameter of $0.1 \mathrm{~m}$ and height of $1.0 \mathrm{~m}$. The reactor is made of stainless steel, and the thickness of the walls is $4 \mathrm{~mm}$. The reactor is heated up with three electric heating elements mounted externally on the wall of the reactor. To prevent heat loss, the outer surface of the reactor is insulated with 200-mm-thick fiberglass and the inner surface is coated with a refractory material. Five pressure sensors and five thermocouples, which measure the change in pressure and temperature during the operation of the reactor, are attached at different heights. Figure 1 shows the experimental setup, the dimensions of the reactor, and the dimensions of the wood pellets used in this work. The biomass from the silo (A) is conveyed to the reactor (B) via a cold screw attached to the silo and a hot screw connected to the reactor. The feed rate of the wood pellets is calibrated by measuring the average flow rates at specified motor speeds. The mass flow rate of air supplied to the reactor is measured with a BROOK air flowmeter. An electric heater is used to heat the compressed air before it is passed into the reactor. The outlet of the reactor is open to the atmosphere and the product gas passes through the flaring system (D) where it is burned to avoid direct discharge of combustible gases to the atmosphere. A sampling line (C) is connected at the top of the reactor and the collected gas samples are measured in an offline SRI gas chromatograph (GC). The GC has a thermal conductivity detector (TCD) and 


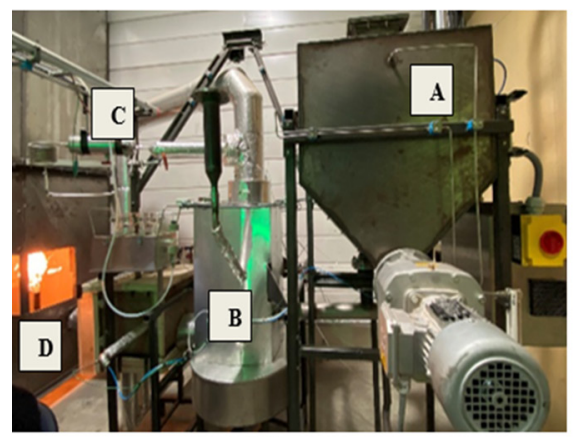

(a)

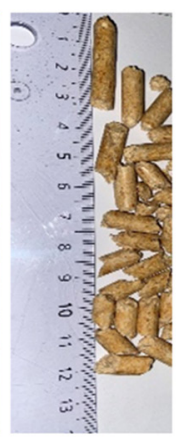

(b)

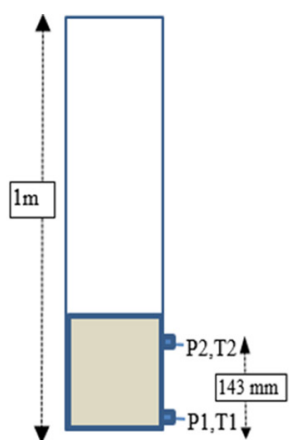

(c)

Figure 1: Experimental setup: (a) experimental rig, (b) wood pellets, (c) reactor dimensions.

Table 1: Properties of the particles.

\begin{tabular}{lllll}
\hline Material & Density, $\boldsymbol{\rho}_{\boldsymbol{p}}$ & Mean diameter & Sphericity, $\boldsymbol{\varphi}_{\boldsymbol{p}}$ & $\begin{array}{l}\text { Particle volume } \\
\text { fraction, } \boldsymbol{\varepsilon}_{\boldsymbol{p}}\end{array}$ \\
\hline Sand & $2600 \mathrm{~kg} / \mathrm{m}^{3}$ & $d_{m}=0.292 \mathrm{~mm}$ & 0.86 & 0.52 \\
\hline Wood pellets & $1300 \mathrm{~kg} / \mathrm{m}^{3}$ & $8.9 \mathrm{~mm}$ & - & 0.44 \\
\hline
\end{tabular}

uses helium as the carrier gas. The GC can measure the major components of the gas sample. Table 1 shows the density (, mean diameter, sphericity (), and volume fraction () of the particles.

The experiment is carried out as a continuous process where the air flow rate is $2 \mathrm{~kg} / \mathrm{h}$ and the feed rate of wood pellets is $2.42 \mathrm{~kg} / \mathrm{h}$. The wood pellets are cylindrical in shape with 6 mm diameter and 3-30 mm length. Sand particles of mean diameter $292 \mu \mathrm{m}$ are used as the bed material. The mean particle size of the sand is obtained using sieve analysis, and the volume equivalent spherical diameter of the wood pellets is calculated from eqn (1):

$$
d_{m, s}=\left(\frac{6 V_{P}}{\pi}\right)^{1 / 3}
$$

where $V_{P}$ is the mean particle volume and is the mean volume equivalent spherical particle diameter.

\subsection{Experimental results}

The air to fuel ratio is maintained at a constant value with a continuous air supply of $2 \mathrm{~kg} / \mathrm{h}$ and a feed rate of wood pellets of $2.42 \mathrm{~kg} / \mathrm{h}$. A static bed height of $0.2 \mathrm{~m}$ is used for the experiment. Initially, the bed material is heated with both an electric heater and pre-heated air up to $750{ }^{\circ} \mathrm{C}$. The temperature of the reactor is maintained at .

Figure $2 \mathrm{a}$ shows the temperature variation in the bed with time measured by the temperature sensor T2. As soon as the wood pellets are fed into the reactor at, volatile gases are released consuming heat from the system. The drop in temperature during volatilization is marked as $\Delta T$. The corresponding pressure variations of the bed, measured by pressure 




(a)

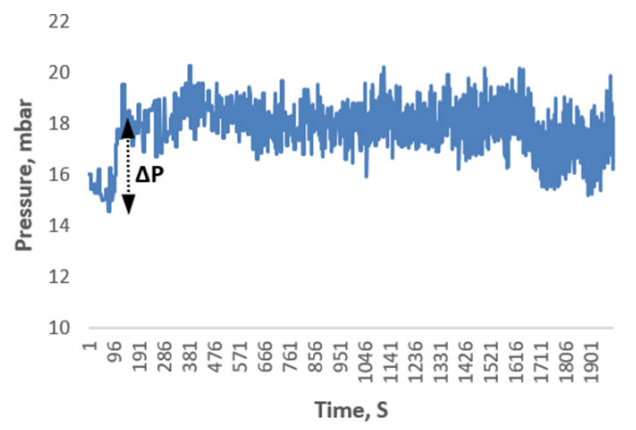

(b)

Figure 2: (a) Temperature and (b) pressure in the bed at air velocity $2 \mathrm{~kg} / \mathrm{h}$.

sensor P1, are shown in Fig. 2b. Since the P1 sensor is located at the bottom of the bed, it gives the total pressure of the bed. The increase in pressure drop from 15 to 18 mbar is due to the increasing wood pellets' load on the bed during the experiment. The pressure after $134 \mathrm{~s}$ is about constant, indicating that the amount of wood pellets added to the bed and the rate at which the wood pellets are converted into product gases and char are constant. Three samples of the product gases are taken at 15-minute intervals and analyzed in the GC. The average molar percentages of the product gases from the three samples are calculated and considered as the representative values of the product gases. The average molar percentages of $\mathrm{CH}_{4}, \mathrm{CO}, \mathrm{CO}_{2}, \mathrm{~N}_{2}, \mathrm{H}_{2}$ and $\mathrm{O}_{2}$ in the samples are $4.97 \%, 17.09 \%, 15.58 \%, 42.5 \%$, $19.08 \%$, and $0.69 \%$, respectively.

\section{COMPUTATIONAL MODEL}

A cylindrical geometry with the same dimensions as the reactor used in the experiment is drawn in AutoCAD and imported to Barracuda. A uniform grid of totally 5120 cells is generated using the default grid setting available in Barracuda. Pressure and flow boundary conditions are defined at the top and bottom of the reactor as shown in Fig. 3. Data points are located at different heights along the reactor to measure pressure, temperature, and gas compositions. Two positions, on-bed and in-bed, at heights of 24 and $4 \mathrm{~cm}$ from the bottom of the reactor, are used to feed biomass into the reactor. The close pack volume fraction is 0.63 and the maximum momentum redirection from collision is $40 \%$. The normal-to-wall momentum retention and tangent-to-wall momentum retention are 0.3 and 0.99 , respectively.

In the CPFD model, it is assumed that the volatilization of biomass is an instantaneous process. As soon as the biomass is fed into the reactor at $700-800^{\circ} \mathrm{C}$, the volatile components are released and the char particles left after volatilization of biomass are gasified at a sufficient temperature and air flow rate. The degradation of biomass into volatile components and char follows various reaction routes. The major reactions and the corresponding kinetics for the gasification process used in this work are taken from literature and are listed in Table 2.

The biomass in the CPFD model is initialized as volatile components, char, and ash. The composition and quantity of the volatile components, char, and ash used in the CPFD model are obtained from proximate analysis of wood pellets as listed in Table 3. 


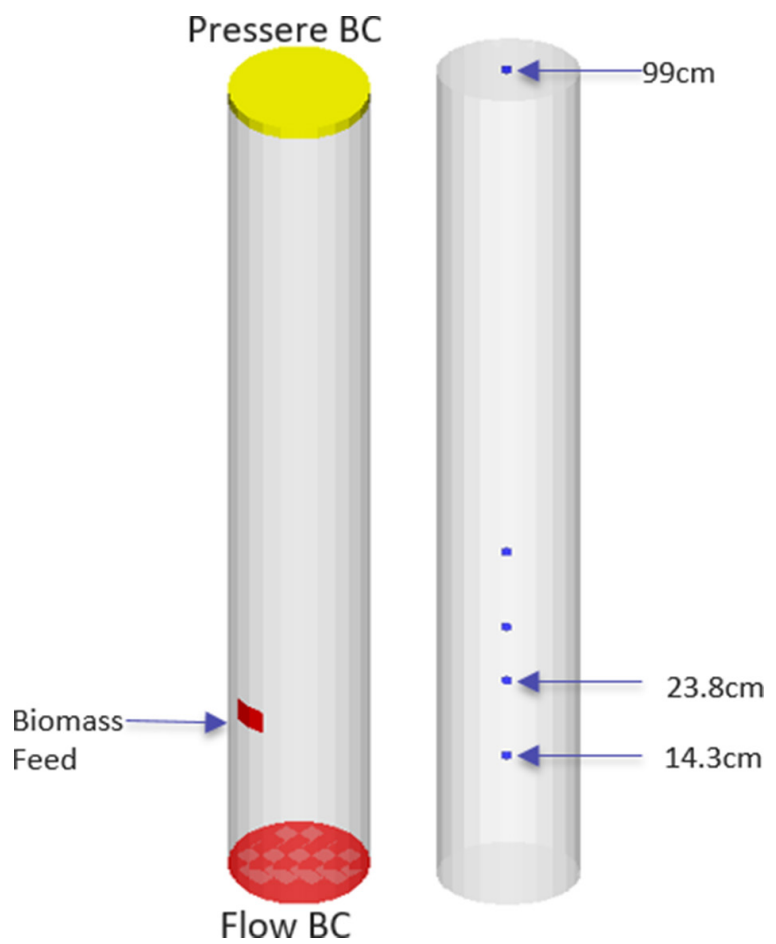

Figure 3: Boundary conditions and transient data points used in the CPFD model.

Table 2: Reactions and rate kinetics used in the CPFD model.

\begin{tabular}{ll}
\hline Chemical reactions & Kinetics \\
\hline $\begin{array}{l}\text { Char partial combustion [13] } \\
2 \mathrm{C}+\mathrm{O}_{2} \leftrightarrow 2 \mathrm{CO}\end{array}$ & $\mathrm{r}=4.34 \times 10^{10} \mathrm{~m}_{\mathrm{s}} \theta_{\mathrm{f}} \exp \left(\frac{-13590}{T}\right)\left[\mathrm{O}_{2}\right]$ \\
$\mathrm{CO}$ oxidation [13] & $\mathrm{r}=5.62 \times 10^{12} \exp \left(\frac{-16000}{T}\right)[\mathrm{CO}]\left[\mathrm{O}_{2}\right]^{0.5}$ \\
$\mathrm{CO}+0.5 \mathrm{O}_{2} \leftrightarrow \mathrm{CO}_{2}$ & $\mathrm{r}=5.69 \times 10^{11} \exp \left(\frac{-17610}{T}\right)\left[\mathrm{H}_{2}\right]\left[\mathrm{O}_{2}\right]^{0.5}$ \\
$\mathrm{H}_{2}$ oxidation $[14]$ & $\mathrm{r}=5.0118 \times 10^{11} \mathrm{~T}^{-1} \exp \left(\frac{-24357}{T}\right)$ \\
$\mathrm{H}_{2}+0.5 \mathrm{O}_{2} \leftrightarrow \mathrm{H}_{2} \mathrm{O}$ & \\
$\mathrm{CH}_{4}$ oxidation $[13]$ & $\mathrm{r}=7.68 \times 10^{10} \mathrm{~T} \exp \left(\frac{-36640}{T}\right)\left[\mathrm{CO}_{4}\right]\left[\mathrm{O}_{2}\right]$ \\
$\mathrm{CH}_{4}+2 \mathrm{O}_{2} \leftrightarrow \mathrm{CO}_{2}+2 \mathrm{H}_{2} \mathrm{O}$ & \\
$\mathrm{Water} \mathrm{gas} \mathrm{shift} \mathrm{reaction}[13]_{\left.\mathrm{CO}_{2} \mathrm{O}\right]} \mathrm{H}_{2} \mathrm{O} \leftrightarrow \mathrm{CO}_{2}+\mathrm{H}_{2}$ & $\mathrm{r}=3.00 \times 10^{5} \exp \left(\frac{-15042}{T}\right)\left[\mathrm{CH}_{4}\right]\left[\mathrm{H}_{2} \mathrm{O}\right]$ \\
$\mathrm{Methane} \mathrm{reforming}[15]_{\mathrm{CH}_{4}+\mathrm{H}_{2} \mathrm{O} \leftrightarrow \mathrm{CO}^{2} 3 \mathrm{H}_{2}}$ &
\end{tabular}


Table 3: Properties of wood pellets (proximate analysis).

\begin{tabular}{ll}
\hline Components & \\
\hline Moisture content & $7 \%$ \\
Volatile matter & $78.75 \%$ \\
Fixed carbon & $14.4 \%$ \\
Ash content & $0.279 \%$ \\
LHV & $18.94 \mathrm{MJ} / \mathrm{kg}$ \\
\hline
\end{tabular}

\section{RESULTS AND DISCUSSION}

In this section, CPFD model validation, influence of the feed positions on the composition of the product gas, and bed hydrodynamics are presented and discussed.

\subsection{Model validation}

CPFD models in Barracuda use the multiphase particle in cell approach, where gas-solid interaction is modelled using the combined Eulerian and Lagrangian approach. With the CPFD setup described in Section 3, simulations are carried out using the Wen and Yu drag model. The simulations are performed for $700 \mathrm{~s}$ with a time step of $0.001 \mathrm{~s}$. The molar composition of the product gas is measured in the upper part of the gasifier. The product gas compositions obtained from the simulation and experiment are compared in Fig. 4. The results show that the CPFD model is predicting the gas compositions very well.

The product gas compositions in the gasification process is dependent on temperature, residence time, interaction of biomass with bed material, and the gasifying agent. The biomass breaks thermally into volatile components, char, and tar following different reaction routes. Figure 5 shows the variations in the product gas composition with time when the wood pellets are fed in-bed. The product gases are more stable in the case of in-bed feed of wood pellets compared to on-bed feed shown in Fig. 6. The wood pellets have a density approximately half of that of sand particles. When the bed is fluidized and the wood pellets are fed close to the bottom of the reactor (in-bed), the wood pellets have sufficient time and contact area to interact with the heated bed material and the fluidizing gas before they are

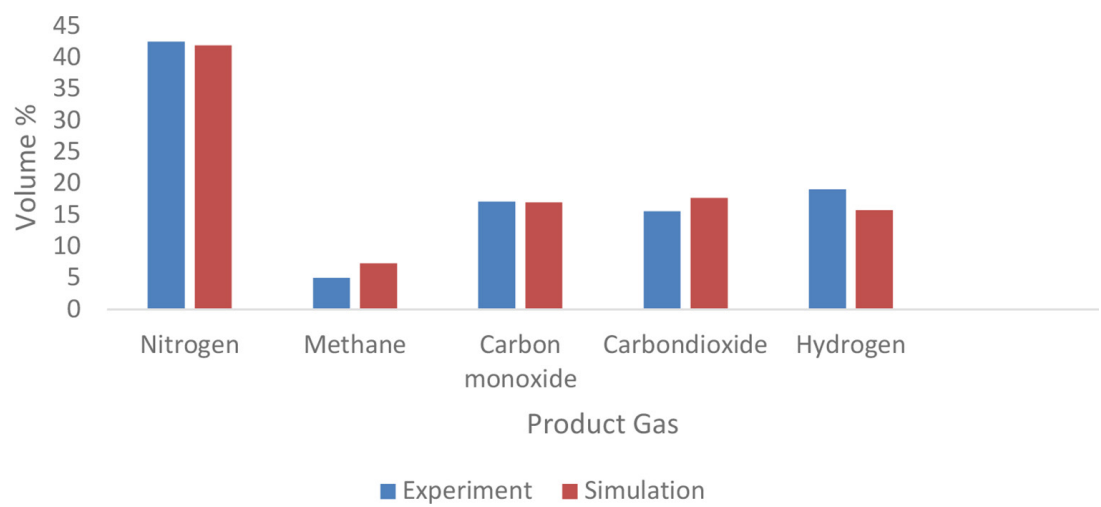

Figure 4: Product gas compositions from the CPFD model and experiment. 


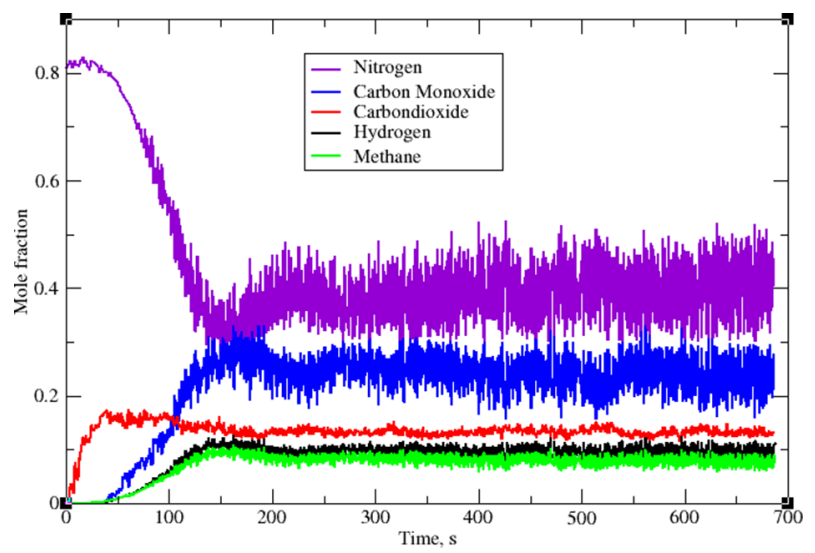

Figure 5: Composition of product gases with in-bed feed of wood pellets.

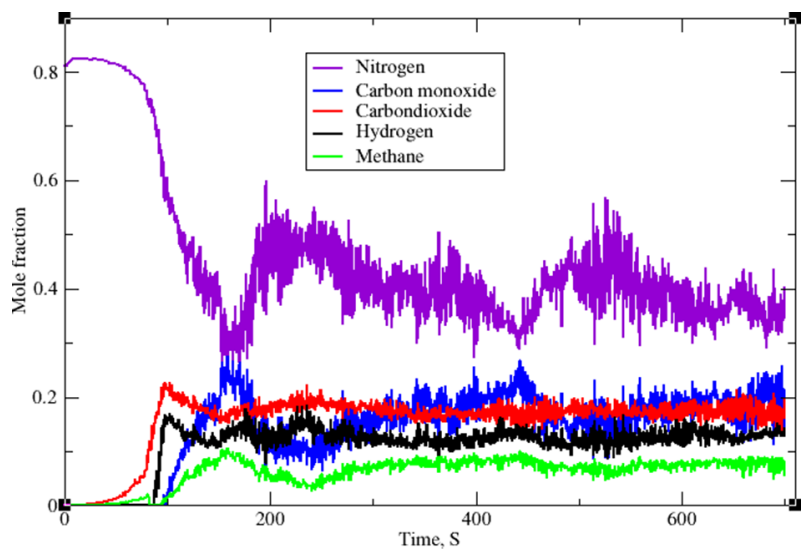

Figure 6: Composition of product gases with on-bed feed of wood pellets.

transported to the upper region of the bed. This means that the wood pellets react in the bed and the solid fuel particles reaching the surface of the bed are mainly char. Mixing of the wood pellets with the bed material is limited in the case of on-bed feeding, and poor mixing results in larger variations in gas composition with time.

The composition of the product gas predicted by the CPFD simulations with on-bed and in-bed feed is compared in Fig. 7. The results show that with in-bed feed of biomass, the molar fraction of $\mathrm{CH}_{4}$ and $\mathrm{CO}$ in the product gas increases from $7.3 \%$ and $17 \%$ to $7.8 \%$ and $23.4 \%$, respectively. The presence of sufficient char inside the bed and longer interaction time of the char with the bed material and oxygen enhance the partial combustion reaction, resulting in a significant increase in $\mathrm{CO}$. The fractions of $\mathrm{H}_{2}$ and $\mathrm{CO}_{2}$ are increased in the case of on-bed feeding compared to the case of in-bed feeding. The main part of oxygen from the gasifying agent (air) is consumed near to the surface of the bed. The oxidation reaction routes of $\mathrm{CO}, \mathrm{H}_{2}$, and $\mathrm{CH}_{4}$ are dominant, which increases the $\mathrm{H}_{2} \mathrm{O}$ and the $\mathrm{CO}_{2}$ fractions. Due to the increase in $\mathrm{H}_{2} \mathrm{O}$ in the free board, the water gas shift reaction increases producing more $\mathrm{H}_{2}$ and $\mathrm{CO}_{2}$. 


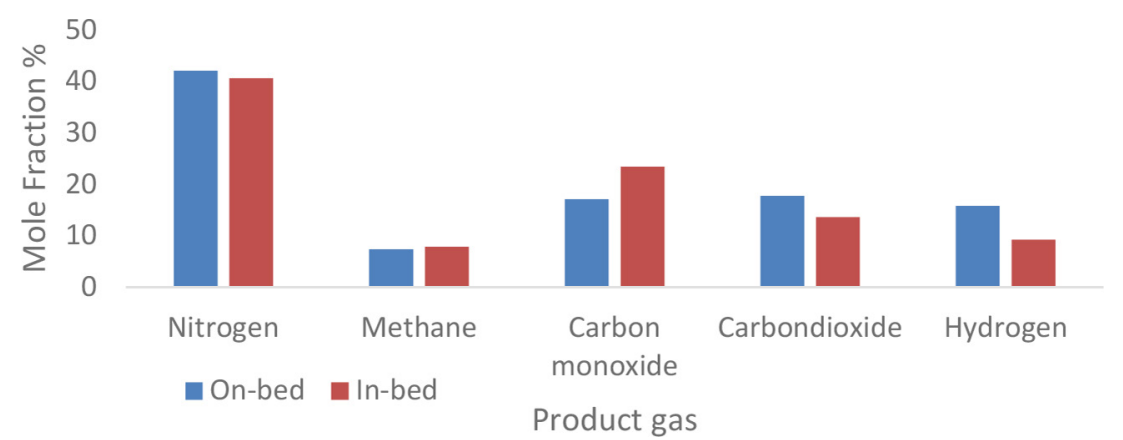

Figure 7: Average product gas compositions for on-bed and in-bed feed.

\subsection{Char conversion}

In the CPFD model, the mass of sand particles is assumed constant, whereas the biomass varies due to the convertion of biomass into a product gas, char, and tar. Thus, change in the total mass of the bed is only dependent on the biomass conversion rate in the bed. The total particle mass of the bed versus time for the on-bed and in-bed feed positions is presented in Fig. 8. For the same amount of biomass feed, the total mass of the particles is higher in the case of on-bed feed compared to in-bed feed. The total mass of the bed increases sharply initially and decreases after a certain period of time. The rapid increase in the total mass of the bed at the beginning is because the conversion rate of the char is slower. At this stage, maximum heat from the system is utilized for volatilization of biomass, followed by the dominant endothermic reactions. After a certain period of time, the exothermic reaction routes compensate the heat loss from the system, which increases the char conversion rate. The total mass of the bed thus increases gradually. It can be seen from Fig. 8 that during the first $100 \mathrm{~s}$, the total mass of the bed increases at the same rate for both cases. After $100 \mathrm{~s}$, increment in total mass of the bed is higher in the case of on-bed feed because the biomass dropped on the surface of the bed does not interact uniformly with the bed material. This results in more char particles to remain unreacted and to accumulate on the surface of the bed, increasing the total mass of the bed.

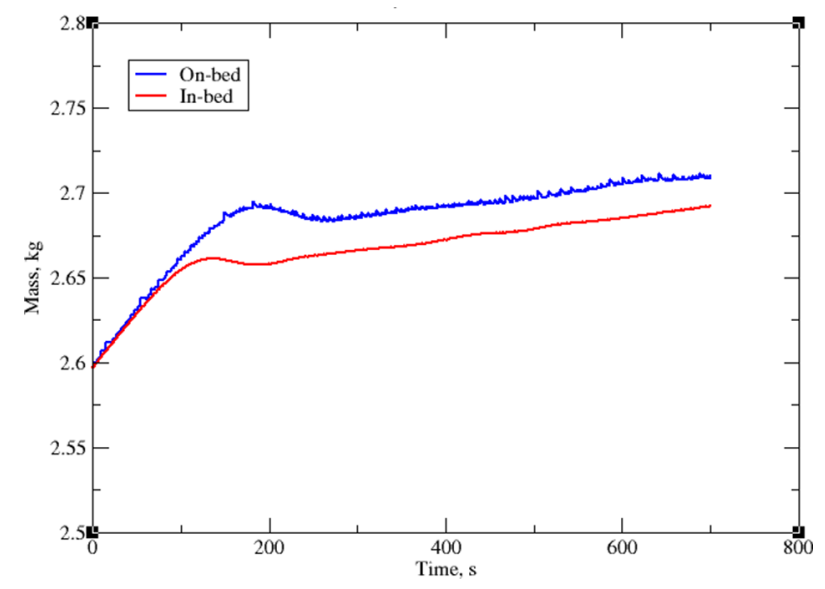

Figure 8: Change in total mass of the bed with time. 

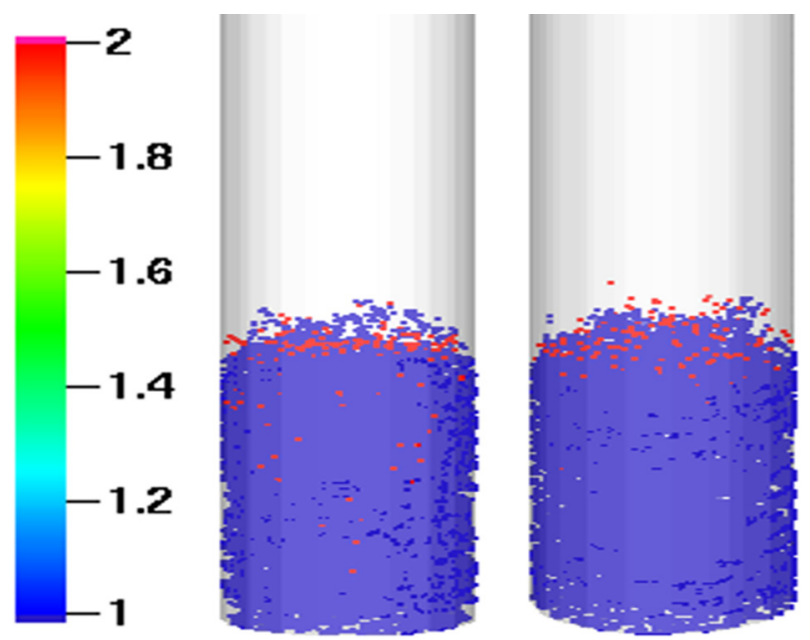

Figure 9: Particle species of the bed at 221 s. In-bed feed to the left and on-bed feed to the right.

\subsection{Bed hydrodynamics}

The density of the wood pellets is approximately half of the density of sand particles. When the bed is fluidized and the wood pellets are fed near the bottom of the reactor, they are transported to the upper region of the bed with time. The movement of fuel particles from lower to upper region is dependent on the superficial gas velocity and the rate of consumption of fuel inside the bed. Figure 9 compares the distribution of fuel particles inside the bed for on-bed and in-bed feed after $221 \mathrm{~s}$. It shows that the fuel particles are mixed with the bed material in the case of in-bed feed. Before the particles are transported to the surface, they have sufficient time to interact with the bed material and air, increasing the gasifier performance as discussed in sections 4.2 and 4.3. With on-bed feed, the fuel particles are segregated and remain accumulated on the surface of bed, affecting the char conversion rate. Mixing of the fuel particles can be enhanced by increasing the superficial gas velocity. However, for maximum gasifier efficiency and provided air to fuel ratio, the increment of superficial gas velocity is limited to operate the gasifier in a specified operating regime [16].

\section{CONCLUSION}

A CPFD model developed in Barracuda VR in this work is used to predict the effect of on-bed and in-bed feed positions on the gasification process. The CPFD model is developed and validated against experimental data from a pilot scale bubbling fluidized bed gasifier. Wood pellets are used as the feed and air as the fluidizing gas. The product gas compositions and char conversion are measured for the on-bed and in-bed feed positons of biomass. The influence of the feed position on the product gas composition, char conversion, and bed behavior is investigated.

The result shows that the volume percentages of $\mathrm{CH}_{4}, \mathrm{CO}, \mathrm{H}_{2}, \mathrm{CO}_{2}$, and $\mathrm{N}_{2}$ in product gas for the on-bed case are $7.3 \%, 17 \%, 15.7 \%, 17.7 \%$, and $42 \%$, respectively, and for the in-bed case, the volume percentages are $7.8 \%, 23.4 \%, 9.1 \%, 13.6 \%$, and $40 \%$, respectively. The increase in the fraction of $\mathrm{CO}$ in the case with in-bed feed is due to the enhanced char partial combustion route. In the case of on-bed feed, the $\mathrm{H}_{2} \mathrm{O}$ fraction increases in the free board, 
which enhances the water gas shift reaction and increases $\mathrm{H}_{2}$ and $\mathrm{CO}_{2}$ fractions in the product gas. It is found that for the same amount of biomass feed, the mass of unreacted char is higher when the biomass is fed above the surface of the bed. In addition, the accumulation of char occurs on the surface of the bed. The residence time of the biomass increases when it is injected near the bottom of the bed, which provides sufficient time for the biomass to interact with the bed material and the gasifying fluid. In the case of in-bed feeding of biomass, the biomass is well mixed and distributed inside the bed, and thus the conversion of char occurs efficiently. The developed CPFD model is able to predict the product gas compositions, fuel conversion, bed hydrodynamics, and the product gas composition under different operational conditions, and will be important for further simulations and design purposes.

\section{REFERENCES}

[1] Jaiswal, R., Agu, C.E., Thapa, R. \& Moldestad, B.M., Study of fluidized bed regimes using Computational Particle Fluid Dynamics. Linköping Electronic Conference Proceedings, 153, pp. 271-276, 2018. https:// doi.org/10.3384/ecp18153271

[2] Timmer, K.J. \& Brown, R.C., Transformation of char carbon during bubbling fluidized bed gasification of biomass. Fuel, 242, pp. 837-845, 2019. https://doi.org/10.1016/j. fuel.2019.01.039

[3] Begum, S., Rasul, M., Akbar, D. \& Naveed, R., Performance analysis of an integrated fixed bed gasifier model for different biomass feedstocks. Energies, 6, pp. 6508-6524, 2013. https://doi.org/10.3390/en6126508

[4] Manyà, J.J., Sánchez, J.L., Ábrego, J., Gonzalo, A. \& Arauzo, J., Influence of gas residence time and air ratio on the air gasification of dried sewage sludge in a bubbling fluidised bed. Fuel, 85(14), pp. 2027-2033, 2006. https://doi.org/10.1016/j. fuel.2006.04.008

[5] Ling, M., Esfahani, M.J., Akbari, H. \& Foroughi, A., Effects of residence time and heating rate on gasification of petroleum residue. Petroleum Science and Technology, 34(22), pp. 1837-1840, 2016. https://doi.org/10.1080/10916466.2016.1230752

[6] Agu, C.E., Pfeifer, C., Eikeland, M., Tokheim, L.-A. \& Moldestad, B.M.E., Measurement and characterization of biomass mean residence time in an air-blown bubbling fluidized bed gasification reactor. Fuel, 253, pp. 1414-1423, 2019.

[7] Wilk, V., Schmid, J.C. \& Hofbauer, H., Influence of fuel feeding positions on gasification in dual fluidized bed gasifiers. Biomass and Bioenergy, 54, pp. 46-58, 2013. https://doi.org/10.1016/j.biombioe.2013.03.018

[8] Jaiswal, R., Furuvik, N.C.I., Thapa, R.K., \& Moldestad, B.M.E., Investigation of the segregation and mixing behavior of biomass in a bubbling fluidized bed reactor using a CPFD model. Linköping Electronic Conference Proceedings, 170, pp. 164-169, 2019.

[9] Fiorentino, M., Marzocchella, A. \& Salatino, P., Segregation of fuel particles and volatile matter during devolatilization in a fluidized bed reactor-I. Model development. Chemical Engineering Science, 52(12), pp. 1893-1908, 1997. https://doi.org/10.1016/ s0009-2509(97)00018-3

[10] Ross, D., Noda, R., Horio, M., Kosminski, A., Ashman, P. \& Mullinger, P., Axial gas profiles in a bubbling fluidised bed biomass gasifier. Fuel, 86(10), pp. 1417-1429, 2007. https://doi.org/10.1016/j.fuel.2006.11.028

[11] Vriesman, P., Heginuz, E. \& Sjöström, K., Biomass gasification in a laboratory-scale AFBG: influence of the location of the feeding point on the fuel-N conversion. Fuel, 79(11), pp. 1371-1378, 2000. https://doi.org/10.1016/s0016-2361(99)00278-1 
[12] Di Celso, G.M., Rapagna, S., Marina, S. \& Zanoelo, E.F., Effect of biomass feed position on the kinetics of devolatilization in a fluidized bed. Chemical Engineering Transactions, 37, pp. 235-240, 2014.

[13] Xie, J., Zhong, W., Jin, B., Shao, Y. \& Huang, Y., Eulerian-Lagrangian method for three-dimensional simulation of fluidized bed coal gasification. Advanced Powder Technology, 24(1), pp. 382-392, 2013. https://doi.org/10.1016/j.apt.2012.09.001

[14] Bates, R.B., Steam-air blown bubbling fluidized bed biomass gasification (BFBBG): Multi-scale models and experimental validation. AIChE Journal, 63(5), pp. 1543-1565, 2017. https://doi.org/10.1002/aic.15666

[15] Solli, K.-A., Thapa, R.K. \& Moldestad, B.M.E., Screening of kinetic rate equations for gasification simulation models. Proceedings of The 9th EUROSIM Congress on Modelling and Simulation, EUROSIM 2016, 142, pp. 105-112, 2016. https://doi.org/10.3384/ ecp17142105

[16] Jaiswal, R., Furuvik, N.C.I., Thapa, R.K. \& Moldestad, B.M.E., Method of identifying an operating regime in a bubbling fluidized bed gasification reactor. International Journal of Energy Production and Management, 5(1), pp. 24-34, 2020. https://doi. org/10.2495/eq-v5-n1-24-34 